\title{
Avaliação da capacidade antioxidante de extratos obtidos do juá-de-cipó (Solanum jussiaei) utilizando líquidos pressurizados e $\mathrm{CO}_{2}$ supercrítico.
}

\section{Heloísa B. Adani ${ }^{\star}$, Ana P. Pereira, Glaucia M. Pastore}

\section{Resumo}

O Solanum jussiaei é um fruto nativo da mata atlântica brasileira, sobre o qual não há relatos na literatura. Sabe-se que os frutos da família Solanaceae são ricos em compostos bioativos, aos quais podem estar relacionadas diversas atividades biológicas. Assim, busca-se com esse projeto fornecer dados para trabalhos futuros que possam explorar o fruto tanto do ponto de vista nutricional quanto tecnológico.

\section{Palavras-chave:}

Solanacea, compostos bioativos, frutas nativas.

\section{Introdução}

O juá-de-cipó (Solanum jussiaei) pertence à família Solanaceae, a qual é caracterizada pela presença de alcaloides.

Entretanto, estudos recentes vêm demostrando a importância dos compostos fenólicos presentes em frutas dessa família, como é o caso da fruta-do-lobo (Solanum lycocarpum) e do juá-açu (Solanum oocarpum). Pereira et al. (2018) caracterizaram os compostos fenólicos presentes nessas duas frutas e verificaram que a capacidade antioxidante de ambas estava diretamente relacionada à presença desses compostos.

Estudos preliminares apontam maior rendimento da extração de compostos bioativos com o emprego de dióxido de carbono supercrítico e de líquidos pressurizados, quando comparada a métodos convencionais.

Portanto, o objetivo desse projeto foi caracterizar o juá-de-cipó quanto a sua composição centesimal e mineral e avaliar o rendimento da extração utilizando dióxido de carbono supercrítico e de líquidos pressurizados

\section{Resultados e Discussão}

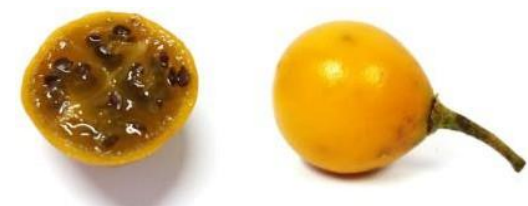

Figura 1. Juá-de-cipó (Solanum jussiaei)

As frações da casca, polpa e sementes foram separadas e liofilizadas durante 48 horas. As amostras liofilizadas foram pesadas e obteve-se o rendimento das frações, sendo o rendimento da polpa $30,25 \%$, da casca $30,07 \%$ e da semente $7,82 \%$.

A composição mineral mostrou que o potássio é o mineral de maior concentração nas três frações do fruto, sendo encontrados $526,80 \mathrm{mg} / 100 \mathrm{~g}$ na polpa. $\mathrm{O}$ cálcio foi o segundo principal mineral, sendo encontrados $27,02 \mathrm{mg} / 100 \mathrm{~g}$ na casca. Esses resultados são superiores aos encontrados por Pereira et al. (2018) para o juá-açú $\quad(300,73 \mathrm{mg} / 100 \mathrm{~g}, \quad 8,00 \quad \mathrm{mg} / 100 \mathrm{~g}$, respectivamente).
Tabela 1. Composição centesimal juá-de-cipó

\begin{tabular}{cccc} 
& Polpa & Casca & Semente \\
\hline Umidade & $82,67 \pm$ & $66,72 \pm$ & $68,51 \pm$ \\
(g/100g) & 0,02 & 0,24 & 0,39 \\
Cinzas & $1,00 \pm$ & $1,32 \pm$ & $0,90 \pm$ \\
(g/100g) & 0,02 & 0,01 & 0,14 \\
Proteínas & $3,09 \pm$ & $3,87 \pm$ & $5,75 \pm$ \\
(g/100g) & 0,1 & 0,12 & 0,16 \\
Açúcares & $8,76 \pm$ & $7,02 \pm$ & $5,26 \pm$ \\
(g/100g) & 0,2 & 0,29 & 0,06 \\
Lipídeos & $0,18 \pm$ & $0,40 \pm$ & $5,28 \pm$ \\
(g/100g) & 0,02 & 0,03 & 0,2 \\
\hline
\end{tabular}

Tabela 2. Avaliação do rendimento global da extração do juá- de-cipó em diferentes temperaturas

\begin{tabular}{cccc}
$\begin{array}{c}\text { Temperatura } \\
\left({ }^{\circ} \mathbf{C}\right)\end{array}$ & Polpa & Casca & Semente \\
\hline & $31,19 \pm$ & $20,50 \pm$ & $9,93 \pm$ \\
$\mathbf{2 5}$ & 0,18 & 0,49 & 0,87 \\
& $29,36 \pm$ & $29,07 \pm$ & $11,78 \pm$ \\
50 & 2,16 & 0,25 & 5,38 \\
& $32,53 \pm$ & $29,08 \pm$ & $16,31 \pm$ \\
$\mathbf{7 5}$ & 2,08 & 1,79 & 1,27 \\
\hline
\end{tabular}

\section{Conclusão}

Está sendo finalizada a avaliação dos compostos bioativos e atividade antioxidante nas frações do fruto. Dessa forma, juntamente com os valores obtidos no rendimento, poderá ser determinada a temperatura ótima de extração do juá-de-cipó.

\section{Agradecimentos}

Agradeço a doutoranda Ana P. Pereira pelo incentivo e suporte durante o projeto e ao SAE/UNICAMP pela concessão da bolsa.

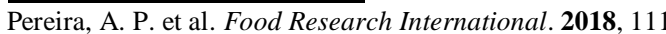

Paes, J. Universidade Estadual de Campinas. 2016 